\title{
Goal gradient during acquisition, partial reinforcement, and extinction of a five part response chain'
}

PAUL W. BECKER AND JAMES L. BRUNING OHIO UNIVERSITY

Seventeen rats were trained to turn 5 wheels in sequence in order to obtain water reinforcement. During acquisition, rate of wheel turning increased as $S$ s approached the goal. During the partial reinforcement phase, the shape of the performance gradient remained about the same. However, a general increase was noted at every wheel except the one closest to the goal. During the extinction phase, the $S s$ stopped responding most quickly to the wheels closest to the goal.

A previous study (Bruning, Becker, \& Tucker, 1965) demonstrated the effects of the presence of cues on the acquisition and extinction of a five part response chain. The present investigation is concerned not only with the effects of different cues, but also with reinforcement schedules as they affect response strength at various points along the response chain.

\section{Method}

Subjects.

The Ss were seventeen female albino rats (SpragueDawley strain), 110-130 days of age. All Ss were maintained on a $231 / 2 \mathrm{hr}$. water deprivation schedule. Apparatus and Pretraining.

The apparatus and the pretraining techniques have been described previously (Bruning, Becker, \& Tucker, 1965).

Acquisition

After the pretraining sessions, Ss were placed in the apparatus and allowed to freely respond for one 5-min. trial each day. As in the previous experiment, the light above wheel No. 5 (farthest from the dipper) was initially turned on. After the Ss had turned all five wheels in sequence, the dipper mechanism activated and delivered .1 cc of water. After the dipper retracted, $\mathrm{S}$ had to again perform the sequence to obtain another reinforcement. Acquisition trials for all animals were under $100 \%$ reinforcement and were continued until performance stabilized (10 5-min. trials).

Partial Reinforcement.

Immediately following acquisition, the Ss were randomly divided into two groups $(N=9 ; N=8)$. In the first group, the lights above the wheels were left operable so that the cue remained. In the second group, the cue lights were switched off. Both groups were then placed on a partial reinforcement schedule in which the terminal reinforcement was given a random $50 \%$ of the time. Thus, on the average, the Ss had to complete the sequence twice to obtain a single drink. Six 5-min. trials were given each S.

\section{Extinction.}

Following the six trials under partial reinforcement, both groups were given six extinction trials. The cue conditions during extinction were the same as were present during the partially reinforced trials.

\section{Results and Discussion}

Data from six trials under each treatment condition (acquisition, trials 5-10; partial reinforcement, trials 11-16; extinction, trials 17-22) were grouped together for purposes of statistical analysis and graphical representation. The analysis of variance was computed to determine the effects of cues, wheel position, and reinforcement condition on performance. This analysis indicated, first, that the main effects of cues was not significant and also that none of the interactions involving cues was significant (cues, $\mathrm{F}=3.83, \mathrm{df}=1 / 15$; cues by treatments, $F<1$, df $=2 / 30$; cues by wheels, $F<1$, df $=4 / 60$; cues by treatments by wheels, $F=1.29$, $\mathrm{df}=8 / 120$ ). Since the presence or absence of cues had no effect, the data presented in Fig. 1 represents the combined performance levels of the two cue groups. A possible explanation for the lack of difference due to cues may be that since the Ss were highly trained at the termination of the acquisition phase, the external light cues became relatively unimportant for successful performance of the chain, and the animals relied almost entirely on various proprioceptive cues.

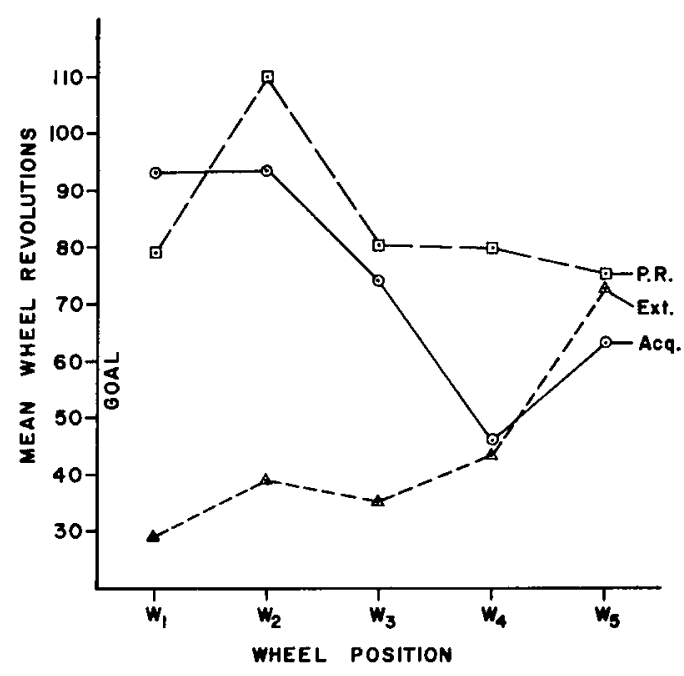

Fig. 1. Mean performance level as a function of wheel position and reinforcement condition. 
Inspection of Fig. 1 reveals that response strength varied considerably as a function of reinforcement condition and wheel position. This was supported by the analysis which showed the effects of reinforcement conditions $(\mathrm{F}=34.7, \mathrm{df}=2 / 30, \mathrm{p}<.001$ ), wheel positions $(\mathrm{F}=8.28, \mathrm{df}=4 / 60, \mathrm{p}<.001)$, and the reinforcement by wheel position interaction $(F=6.34$, $\mathrm{df}=8 / 120, \mathrm{p}<.001)$ all to be significant.

As was noted in the previous study, the general trend during acquisition was for response strength to increase as the $S$ neared the goal. The change to partial reinforcement resulted in an increased rate of wheel turning at every wheel except No. 1. Also, as can be noted from Fig. 1, the tendency was for some flattening of the goal gradient to occur. During extinction, the results were consistent with those of the previous study in that the responses most closely associated with the goal were the first to extinguish.

In addition to the wheel turns made by the Ss, the number of sequences completed was also recorded. These results were generally consistent with those relating to wheel turning. During the acquisition phase, the mean number of sequences completed during the last six trials was 86 ; during partial reinforcement, the number rose to 116 , and during extinction, it dropped to $39(\mathrm{~F}=4.43, \mathrm{df}=2 / 34, \mathrm{p}<.025)$.

\section{Reference}

Bruning, J. L., Becker, P. W., \& Tucker, R. C. The effect of goal proximity on acquisition and extinction of a five part response chain. Psychon. Sci., 1965, 3, 211-212.

Note

1. Portions of this paper were read at the 1965 Midwestern Psychological Association meeting in Chicago. 